Language

development in

children with

Down's

syndrome

\section{Reasons for optimism}

\section{Sue Buckley}

\author{
Principal Lecturer in Psychology \\ Director, Sarah Duffen Centre \\ University of Portsmouth
}

Research during the last ten years has begun to unravel some of the reasons for the difficulties that most children with Down's syndrome experience when learning to talk. The studies reveal a variety of specific difficulties that will impede progress over and above any effects of general cognitive delay. Most of the research to date is descriptive, outlining the delays and differences usually seen in the language performance of children and teenagers with Down's syndrome and some of the possible reasons for these delays and differences. There are very few published studies of the long-term effectiveness of remediation as yet, despite the fact that many of the specific difficulties described should be remediable to at least some degree. This article focusses on the research that, in the author's view, has the most relevance for remediation strategies and some of the practical implications are set out at the end of the article. It also draws attention to the complex and interactive nature of language learning and its significance for cognitive development. It is the author's belief that if interventions based on our current knowledge were implemented throughout childhood many young people with Down's syndrome would have much better speech, language and cognitive skills and consequently enjoy a much improved quality of life.

(C) 1993, 1999. The Down Syndrome Educational Trust Down Syndrome Research and Practice

1993, 1, 3-9
Language is usually delayed

Descriptive accounts of the development of children with Down's syndrome almost always draw attention to the delays to be expected in their speech and language development . Despite a wide range of individual differences, most children are late in saying their first words, their vocabulary grows more slowly than in ordinary children and although they use the same range of two-word phrases as all children, they have difficulty in mastering the many rules for talking in grammatically correct sentences (Rondal 1988, Miller 1988).

This leads to the speech of many teenagers and adults with Down's syndrome being restricted to short telegraphic utterances (keywords without the function words, for example "went swimming Dad" rather than "I went swimming last night with my Dad"). They also tend to have difficulty in pronouncing words clearly (Bray \& Woolnough 1988).

The combined effect of talking in telegraphic utterances and poor pronounciation often makes young people with Down's syndrome difficult to understand, especially if they are trying to talk to strangers out in the community rather than to those familiar with them at home or in school (Buckley \& Sacks 1987).

\section{The importance of language}

This difficulty with learning to talk adequately has several potentially serious consequences for the children's development from the end of the first year of life. Learning to talk enables a child to communicate in more effective and complex ways, to gain ever increasing amounts of information about the world and to use language for mental processes such as thinking and remembering.

\section{Language to communicate}

Using speech, we are able to have control over our lives. We can ask for what we want or need, tell people how we feel, ask for information, share our pleasures and our worries, make friends and enjoy our social lives. If we have only limited ability to talk we will be more isolated from others and our social and emotional lives impoverished.

\section{Language for learning}

Once a child begins to understand spoken language the scope for learning about the world expands enormously. We can talk to the child about everything we do, we can talk about what we are going to do and what we did yesterday or last week. We can talk about many things that are outside the child's range of actual experience, such as what the postman does at the sorting office or the doctor at the hospital, what astronauts do or why the wind blows. Many psychologists have emphasised the importance of language for teaching concepts and ideas, the tools for thinking, to children (Vygotsky 1986, Bruner 1983). Any child with a delay in learning to communicate in a language is going to be seriously disadvantaged in being able to gain knowledge about the world.

\section{Language for cognitive functions}

Psychologists have also drawn attention to the way in which language and speech are used for cognitive functions. Once we have begun to master a language, we think in terms of words, we reason, recall and do mental arithmetic in words either silently or aloud. For example, according to our current understanding of short-term memory functioning, (which is 
essential for most mental processes), it is based on silent speech and develops as children's speech facility increases. Storage and recall from long term memory is also dependent on organising the information on the basis of meanings conveyed by language i.e grouping items into similar classes such as fruit or clothes. Currently there is considerable interest in the inter-relationships between the development of speech, language and memory abilities (Gathercole 1993).

\section{The links between language and cognition}

Children with Down's syndrome are expected to show cognitive delay, to be slower in developing their awareness and understanding of the world and to think reason and remember. This cognitive delay may be in part the consequence of the language learning difficulties. Any serious language delay will inevitably result in increasing cognitive delay as language is such a powerful tool for gaining knowledge and for understanding, thinking, reasoning and remembering. Conversely the more we can do to overcome the children's language learning and speech difficulties then the better equipped they will be to learn and improve their cognitive abilities.

\section{Learning to talk}

The focus of this article is on learning to talk, but learning to talk is not the only form of communication available to us, though it is the most powerful, and research suggests that it is built on babies' experience of communicating in the first year of life in several ways.

\section{The first year \\ Communicating before talking}

Babies have experience of communicating in the first months of life and they soon learn that they can control their parent's behaviour, for example, by smiling and crying. They begin to understand people, their behaviour and moods and to know when someone is happy, sad or angry from the clues provided by tone of voice, facial expression and behaviour. This is the first step on the pathway of social and emotional development.

\section{Early conversations}

Once babies begin to smile parents begin to have interactions with them that are like conversations. We smile, coo and talk to the baby and tend to do this in conversational style, waiting for the baby to smile, gurgle or babble after each of our actions. These exchanges are usually a source of pleasure to both partners and strengthen the emotional bonds. If adults spend time in these baby conversations, it is the child's first experience of pleasurable "talk" with an adult and they begin to understand that being able to communicate is fun and that it is worth becoming skilled at this activity. They also learn to look, listen and take-turns in the conversation, all essential skills for effective communication when talking.

\section{Initiating conversations}

Research has shown that babies with Down's syndrome, while a little later to smile and enter into these conversations, are as interested as ordinary babies in these social games and spend the same amount of time engaging adults in this kind of activity in the middle of the first year of life (for a review see Berger 1990). However the studies have shown that when ordinary babies begin to spend proportionately more time exploring their visual world the babies with Down's syndrome do not do this to the same extent. They are still more interested in people. Nor do they move on to use eyecontact to engage the adult in their activities at the end of the first year of development, in a way which has been described as referential eye-contact.

\section{Language learning opportunities}

When babies make referential eye-contact and draw the adult's attention to what they are doing, the adult tends to talk and give the baby the words to describe what they are doing or thinking about, so the babies' skill at referential eyecontact may influence the amount of language learning opportunities experienced. Studies by Olwen Jones (Jones 1980) have also shown that the babies are not always skilled at turn-taking. They tended not to leave predictable pauses when babbling and vocalising making it difficult for their mothers to contribute to the conversation. This may also have a negative effect on language learning opportunities.

\section{Cracking the code}

If a baby is to learn to talk he or she has to "crack the code". Imagine yourself in a foreign country staying with a family who speak no English and you do not speak their language at all. Think how you would begin to pick up the foreign language. You would be likely to learn some nouns and verbs for everyday objects, people and actions. Your hosts would probably help by holding up objects and naming them, pointing and gesturing. You will learn by watching and trying to guess the probable content of their communications from the context in which they are happening. You will hear a request and see the following action as someone passes the salt at the table or goes to the kitchen to wash the dishes. Social words like hello and goodnight, please and thankyou, should not be too difficult to pick up and before long you will be able to get by, managing to make yourself understood by stringing the keywords you have learned together but it will take much longer to master the grammar and the syntax of the language. A baby learning his or her first language faces a similar task and proceeds in much the same order.

\section{First words}

The process of learning first words and building up a vocabulary is referred to as lexical acquisition. There has been quite a lot of research on the lexical development of children with Down's syndrome, looking at the speed of learning words and the factors that may affect this.

\section{Understanding}

Before being able to use words to talk, the baby has to begin to learn their meanings. In order to do so the baby needs to hear language in situations where the context and actions will give him the necessary clues to 'crack the code'. It is no coincidence that the first words that all children understand and use are those that refer to objects, people and experiences in their everyday world. These are the words they have heard used in context day after day.

Research in this area of early conceptual development is reviewed by Mervis (1990). She concludes that there are three major similarities between children with Down's syndrome and ordinary children at this stage. First, young children initially believe that when an adult points or indicates an object for which the child does not already have a name, the accompanying word refers to the whole object 
rather than some attribute of the object. Second, the first words that all the children learn are words for objects that either are capable of moving independently or can be manipulated by the child. Thirdly, the first set of concrete nouns acquired by both sets of children represent basic level categories, that is those that are the easiest to identify perceptually.

Mervis draws attention to some evidence for differences in the way mothers of children with Down's syndrome and mothers of ordinary children are talking to their children at this stage and suggests this may affect their rate of vocabulary acquisition and conceptual development. (This important area of early cognitive development will be discussed in more detail in the next issue of the Journal).

\section{Starting to talk}

Once children understand some words they soon begin to try using them to communicate.

\section{Speech production delay}

A number of studies have drawn attention to the delay in beginning to talk in children with Down's syndrome relative to their level of language comprehension. The most recent research available on the development of expressive speech in children with Down's syndrome is that of Jon Miller and his colleagues at the Waisman Centre, University of Wisconsin USA.

Miller and his colleagues studied the productive abilities of 56 children with Down's syndrome (Miller et al. 1987a,b). The children's receptive and expressive language skills were compared with measures of their non-verbal cognitive abilites. They report that there was no evidence of productive delay until the stage at which first words should be produced.

Below 18 months of age language comprehension and production skills were equal to non-verbal cognitive ability for all the children, but from 18 months on an increasing proportion of the children showed delay in language production relative to their language comprehension and their language comprehension was equal to their non-verbal cognitive ability. The proportion of children showing this profile increased with age, accounting for $60 \%$ to $75 \%$ of the children over 18 months of age. The remaining $40 \%$ to $25 \%$ of children with Down's syndrome had no delay in their expressive language skills relative to their level of language comprehension.

\section{Signing}

In a recent cross-sectional study (Miller et al 1991), they measured the spoken and signed vocabularies of 44 children with Down's syndrome and 46 typically developing children, from 12 to 27 months in mental-age. The results showed that as a group, the children with Down's syndrome acquired significantly fewer spoken words as their mentalage increased than the ordinary children. However, when the signed-only vocabulary was added to the spoken vocabularies of the children with Down's syndrome, the group differences were no longer significant.

In a further longitudinal study of 20 children with Down's syndrome and 23 ordinary children, parents recorded their vocabulary (spoken and signed) over a period covering 12 months of mental-age development. Overall, the children with Down's syndrome did not acquire vocabulary at the same rate as the ordinary children but within both groups there was wide variation in rates of progress (Miller et al 1992).

\section{Variability in all children}

The researchers pooled the data for all the children and were able to identify three groups, which they describe as slow, average and fast in their rate of vocabulary acquisition. In the average group there were 9 children with Down's syndrome and 11 ordinary children, in the slow group 11 with Down's syndrome and 4 ordinary and in the fast group 8 ordinary children only. These results emphasise the wide variation in language development seen in all children. By the end of the study, 4 children thought to be showing ordinary development twelve months earlier were now classified as language delayed and in need of remedial help. 9 children with Down's syndrome were in the average group and were learning words at about the same rate as almost half the ordinary children.

The data show that all children vary widely in the rate at which they acquire vocabulary and that the variability cannot be explained by rate of cognitive development as measured by the Bayley Scales of Infant Development at this stage. On average the fast group learned 38 words, the average group 23 words and the slow group 5.6 words per month of mental age gain. Miller suggests that these differences should be the next focus for research effort and one possibility to be explored is the amount and style of mother's speech to their children as this has recently been shown to affect the rate of vocabulary acquisition in ordinary children (Harris 1992)

In an earlier study Miller and colleagues showed that children with Down's syndrome do show a vocabulary spurt like other children, that is a rapid increase in the rate of acquisition of new words, but that this occurs later than in ordinary children in relation to mental-age (on average at $30 \mathrm{mths} M A$ rather than $17 \mathrm{mths} M A$ ) and when they have acquired some 45 words, whereas the spurt in ordinary children is at about 20 words.

\section{Language-learning situations}

Researchers have already devoted quite a lot of effort to investigating the way in which mothers talk to children with Down's syndrome but these have mainly been experimental studies in which mothers and babies have been filmed in a play session. Some reviewers conclude that these studies have not shown any consistent significant differences in styles of mothers' speech to the children if children are at the same stage of speech production (e.g. Rondal 1987). Others do suggest that the verbal and non-verbal interactions between mothers and children with Down's syndrome may be influenced by the children's difficulties in ways that may affect language learning (Berger 1990, Mervis, 1990) No studies have actually looked at the variations in amount or style of daily talking between mothers and children with Down's syndrome to see if this influences their progress and explains some of the wide variations in progress reported by Miller (1992).

\section{Two words together}

Once children have established a single word vocabulary of about 50 words they begin to use two-word phrases. While children with Down's syndrome use the same range of twoword constructions in their speech they tend to have a larger single word vocabulary when they begin to put two words 
together (about 100 words rather than the 50 word vocabulary size that is usual for ordinary children). Another study by Miller and his colleagues illustrated that compared with ordinary children they continue to have a larger overall vocabulary for the length of utterance used but show more difficulty beginning to pick up and use grammatical markers and syntax rules (Miller 1988).

\section{Grammar and syntax}

This difficulty in learning to understand and use increasingly complex grammar and syntax continues and most teenagers with Down's syndrome exhibit very immature development. The research in this area is reviewed in a recent chapter by Anne Fowler (Fowler 1990). She suggests that while children with Down's syndrome are able to build up a lexicon of words, they may have a specific difficulty with acquiring the grammar and syntax of language, which they are not able to overcome, and that this may be a ceiling imposed by the genetic condition.

She suggests that dichotic listening studies indicate impairment in the usual left-hemisphere speech areas of the brain. However this may be the result of language delay rather than a cause according to evidence from the study of the hearing impaired (Sacks 1988) and from more recent evidence from more linguistically able people with Down's syndrome (Piccirilli et al. 1991).Oliver Sacks suggests that it is only when rule-governed language is established that the left hemisphere centres come into play, reminding us of the dynamic nature of all functional brain development.

\section{Improving with age}

In a recent study Robyn Chapman and colleagues (Chapman et al 1992) produced evidence to contradict Fowler's view that there is a ceiling on linguistic development. They studied the development of expressive syntax in two groups, 49 children with Down's syndrome aged from 5 to 20 years and 49 ordinary children aged 2 to 6 years. The two groups were matched for non-verbal mental-age and mother's occupational status. They recorded narrative and conversational samples from all the children.

The length of utterances produced increased with age for both the groups and the older children with Down's syndrome showed continuing syntactic development up to 20 years of age. The language recorded in the two teenage groups included the use of complex sentences containing more than one clause. However they did find evidence of difficulties with grammatical morphology. The children with Down's syndrome omitted more words than the ordinary children and all the words omitted were from closed class grammatical categories.

Chapman concludes that language therapy should continue to late adolescence and should focus on grammatical morpheme use and on complex sentence structures. (The author's research on the effectiveness of language intervention in adolescence to be reported in the next issue of the Journal has focussed on teaching these two aspects of language production).

\section{Working memory}

Recent research which has reported the poor development of phonological working memory in children with Down's syndrome (Hulme \& Mackenzie 1992) may be relevant to understanding the children's difficulty in learning the rules for grammatical morphology and syntax. In order to learn these rules from listening to their use in adult speech, the child will often need to be able to hold sentences of six or more words in working memory while they process them for meaning. They are most unlikely to be able to do this even as teenagers, with average digit spans of only 3 digits at this age (Buckley 1993).

Hulme's work on the development of working memory in ordinary children (Hulme 1984) suggests that the growth of the phonological loop is related to increases in speech rate as children get older. This implies a complex and circular problem for children with Down's syndrome as their speech production difficulties are considerable and they do not show the rapid increase in rate of speech production seen in ordinary children.

Recent work suggests a link between speech production skills and phonological working memory in ordinary preschool children (Adams \& Gathercole 1993) and work in this area may make an important contribution to understanding the early cognitive and language learning difficulties of children with Down's syndrome.

\section{Intelligibility \\ Production skills}

While a number of studies have reported on the poor intelligibility of the speech of many of the children and adults with Down's syndrome, most reviewers conclude that the babble patterns of the babies are normal and that most of the phonological and articulatory patterns are immature.

While the complexity and frequency of babble patterns in ordinary infants predicts their later acquisition of speech and language skills, a recent study reported no such relationship evident in the children with Down's syndrome (Miolo et al. 1992). Better babbling did not lead to better talking. Some specific difficulties seem to affect speech production even though babble patterns are normal.

All motor skills require practice to improve them and one of the issues relevant here may simply be lack of practice. Children with Down's syndrome do not usually begin to talk as early as other children and even when they do get started they do not talk as much. I suspect that the difference in the amount of talk that the average five year old with Down's syndrome and the average ordinary child produces in a day would be very considerable. I suspect the child with Down's syndrome is getting less than half the daily practice. While practice may help to improve the clarity of production it is unlikely to solve the problem entirely as research studies, including the work of Christine Hamilton (Hamilton 1993) reported in this issue, suggest that the speech-motor problems are complex.

\section{Effects of poor intelligibility}

The tendency of teenagers with Down's syndrome to speak in short utterances may be influenced by their experience. In one study (Bray \& Woolnough 1988) the longer and more complex the utterances the teenagers used, the less likely they were to be understood. Their pronounciation was better and thus they were more intelligible when using one and two word utterances This would lead to the habit of speaking in one and two word phrases even if they were capable of generating more complex sentences since the main purpose of communication is to be understood. 
Christine Jenkins' analysis (Jenkins 1993) of the difference between comprehension and expression in the children she reports in this issue suggests that the profile could reflect the patterns of speech and language therapy that the children have received.

It is probable that the poor intelligibility leads to distortions in conversational style even in early childhood, with a tendency for adults to ask closed questions, to prompt and fill in for the child and generally to be too helpful, preventing the children from learning how to do better for themselves. Changes in styles of responding to the children when they are at a two-word level of production could contribute to their difficulty in learning grammar and syntax.

\section{Using language}

We have already touched on issues related to the children's skill in actually using language in considering baby interactions and intelligibility issues.

\section{Conversations}

At the pre-verbal stage turn-taking seems less well established than in ordinary children and leads to more vocal clashes when one partner interrupts or speaks over the other. However when children with Down's syndrome are talking at the one and two-word level they seem to understand the conversational skills quite well, using a range of utterrance types, responding to question forms and attempting to keep conversations going and repair them when misunderstood (e.g. Coggins et al. 1983, Peskett \& Wootton 1985, Rondal 1988).

\section{Social sensitivity}

The children generally seem keen to communicate and to interact, perhaps showing continuation of their interest in people in the first year of life. The social skills and behaviour of the majority of children with Down's syndrome are good for their developmental age, as is their understanding of other people and what they are thinking and feeling (BarenCohen et al. 1992). Parents often comment on the empathy and social sensitivity of teenagers with Down's syndrome (Buckley \& Sacks 1987).

However as they get older, the experience of often not being understood when talking may deter the young people in social situations. Bray \& Woolnough (1988) reported that the teenagers were much less likely to initiate conversations or to attempt to repair them than their conversational partners. Sometimes teenagers do not have the skills, language or confidence to enable them to introduce themselves to strangers or engage in general everyday social conversations.

\section{Emotional needs}

Many teenagers and young adults experience social isolation, in the sense of not having close friends to chat to and share worries with. This is in part the result of the lack of adequate vocabulary and language skill to make friends and talk about their experiences. This can lead to the creation of fantasy friends and the need to engage in fantasy play to deal with worries even into adult life. Buckley \& Sacks (1987) found half the teenagers in their study either had fantasy friends, engaged in fantasy play or talked aloud to themselves when alone.

\section{Main conclusions}

Hearing loss, visual defects and motor delay may be having a significantly delaying effect on the progress of many of the children from infancy.

The ability of babies with Down's syndrome to learn to talk may be adversely effected in the first year of life by their tendency to have less well-developed conversational skills and to be less efficient at setting up language learning situations with adults. This means they experience less opportunities for beginning to understand a vocabulary.

While toddlers with Down's syndrome learn word meanings in the just the same way as other children, they are learning new words and expanding their total vocabulary at a slower rate than ordinary children. They are not increasing their vocabulary as fast as they should in relation to their own mental-age progress.

There may be some differences in the way that mothers interact with and talk to their children with Down's syndrome, prompted by differences in their babies' skills and speech, which could be adversely affecting their progress.

Intervention including the use of signing reduces the differences in lexical acquisition between children with Down's syndrome and ordinary children and brings most children with Down's syndrome within the normal range at this stage.

Most children with Down's syndrome seem to have considerably more difficulty in learning the grammar and syntax of the language than with learning lexical items.

Most children with Down's syndrome show specific productive delays, first in being able to say single words and then in being able to produce sequences of words. Their comprehension for vocabulary, grammar and syntax is is usually greater than their productive skill suggests.

Most children will have difficulty speaking clearly, showing both phonological and articulatory difficulties.

\section{Implications for intervention}

\section{Physical care}

It is essential for the children to receive first class physical care and to receive physiotherapy to try to keep motor progress near to normal milestones otherwise the baby will not be able to handle objects and explore. This will lead to cognitive delay and language learning delay. Secondly any sensory impairments need to be identified and effectively treated as early as possible. The significance of these impairments, particularly hearing loss, in explaining some of the delays seen in cognitive and language development are still being underestimated in most of the research literature.

\section{Sensitivity}

In the first year of life, it is important to draw parents attention to the importance of early conversations and to encourage them to follow the babies' cues, not to overwhelm them with too much physical or verbal stimulation without allowing the baby to join in and respond. Secondly it will be important to explain how an early lexicon is learned and the value of play sessions for encouraging exploration and to overcome the babies' tendency to initiate fewer opportunities for language 
learning. It may be helpful to explain the importance of talking about what the baby is looking at or doing, so again letting the baby lead the interaction if possible.

Adults need to continue to be sensitive to the child's efforts to communicate throughout childhood in order to encourage them to keep trying at a task which is likely to be difficult. Adults need to be conscious of their style of interacting and be sure to try to appropriately expand two and three word utterances, to encourage conversational sequences and to avoid asking closed questions or being too helpful in a way that may make the immediate exchange successful in terms of getting the message accross, but not in terms of encouraging language development beyond telegraphese. If a child can make themselves understood with a mixture of single words and signs there may be no motivation to learn to speak in better sentences.

\section{Signing}

Miller's evidence (Miller et al. 1991) certainly supports the value of teaching sign to help to reduce the negative effects of productive delay, to keep up the rate of vocabulary comprehension and to develop the ability to communicate in a symbolic way. It will be especially important for the many children with Down's syndrome who have a hearing loss.

However it is also important to encourage children to make as many sounds as possible and to practice their oral-motor skills. This can be done in fun ways with sound games and nursery rhymes. The establishment of good feeding and chewing patterns and encouraging nose rather than mouth breathing may improve voice quality and intelligibility.

\section{Symbols and print}

Using written language systems can have a variety of benefits. Symbols and words can prompt production and be used to greatly increase productive practice. They may help to overcome the auditory memory problems even at the stage of first word learning. Later they can be used to prompt and help the child to practise longer utterances. This may help improve the ability to spontaneously produce intelligible sentences. Print is a very powerful tool for language teaching as the child can be taught to read, understand and practice grammatically and syntactically correct utterances (Buckley \& Bird 1993).

\section{Language needs to be taught}

The children will benefit from language teaching right from baby hood. In addition to being encouraged to sign, parents can be informed about all aspects of language development so that they can help their child. They are likely to be by far the most effective teachers for their own children. They can be encouraged to continue to consciously expand the child's lexicon and then go on to teach grammar and syntax. Language teaching should continue through teenage years if necessary. Our experience is suggesting that children who have received intervention from birth including signing and reading instruction may not need continued intervention into teenage years.

\section{References}

Adams \& Gathercole (1993) Phonological working memory and speech production skills in pre-school children. In Press.
Baren-Cohen, S., Tager-Flusberg, H .\& Cohen, D. (Eds) (1992) Understanding other minds: perspectives from autism . Oxford University Press

Berger,J. (1990) Interactions between parents and their infants with Down syndrome. In Cicchetti, D. \& Beeghly, M. Children with Down Syndrome: a developmental perspective. Cambridge.

Bray,M. \& Woolnough,L. (1988) The language skills of children with Down's syndrome aged 12 to 16 years. Child Language Teaching and Therapy 4 311-324.

Bruner,J. (1983) Child's Talk: Learning to use language. Oxford.

Buckley,S. \& Sacks,B. (1987) The Adolescent with Down's syndrome: Life for the teenager and for the family . Portsmouth UK: Portsmouth Polytechnic.

Buckley,S. (1993) Improving the speech of teenagers with Down's syndrome. Down's Syndrome: Research and Practice 1 (2).

Buckley,S. \& Bird,G. (1993) Teaching children with Down's syndrome to read, Down Syndrome Research and Practice 1 (1) 34-39.

Chapman,R. Schwartz,S. E., Kay-Raining Bird,E. (1992) Language production of older children with Down's syndrome. Paper presented at the 9th World Congress of the International Association for the Scientific Study of Mental Deficiency. Queensland, Australia, August 1992.

Coggins, T., Carpenter,R.L. \& Owings,N.O.(1993) Examining early intentional communication in Down's syndrome children and non-retarded children. British Journal of Disorders of Communication 18(2) 98-106.

Fowler,A. (1990) Language abilities in children with Down syndrome: evidence for a specific syntactic delay. In Cicchetti,D. \& Beeghly, .M. Children with Down Syndrome: a developmental perspective . Cambridge.

Gathercole,S. (1993) Working memory and language processing. LEA.

Hamilton,C. (1993) Investigation of the articulatory patterns of young adults with Down's syndrome using electropalatography. Down Syndrome Research and Practice, 1 (1) 15-28.

Harris,M. (1992) Language experience and early language development: from input to uptake. LEA.

Hulme,C. \& Mackenzie,S. (1992) Working memory and severe learning difficulties. LEA.

Jenkins, C. (1993) Down Syndrome Research and Practice, 1 (1) 10-14.

Jones, O. (1980) Prelinguistic communication skills in Down's syndrome and normal infants. In Field,T., Goldberg,D., Stern,D.\& Sostek,A. (eds) High Risk infants and children:Interactions with adults and peers. Academic Press. Mervis,C. (1990) Early conceptual development of children with Down's syndrome. In Cicchetti,D. \& Beeghly,M. Children with Down Syndrome: a developmental perspective. Cambridge.

Miller,J., Streit,G., Salmon,D. \& LaFollette,L. (1987a) Developmental synchrony in the language of children with Down syndrome. Paper presented at the Annual Convention of the American Speech-Language-Hearing Association, New Orleans, Louisiana.

Miller,J.F. (1987b) Language and communication characteristics of children with Down syndrome. In Pueschel,S., Tingey,C., Rynders,J., Crocker,A. \& Crutcher,D. (Eds) New perspectives on Down syndrome, pp. 233-262. Baltimore: Brooks Publishing Co.

Miller,J. (1988) Developmental asynchrony of language development in children with Down syndrome. In Nadel,L. (Ed) Psychiobiology of Down syndrome, Bradford: MIT. 
Miller,J., Sedey,A., Miolo,G., Murray-Branch,J. \& Rosin,M. (1992) Vocabulary acquisition in young children with Down's syndrome. Paper presented at the 9th World Congress of the International Association for the Scientific Study of Mental Deficiency. Queensland, Australia, August 1992.

Miller,J., Seeley,A., Miolo,G., Rosin,M., Murray-Branch,J., (1991) Vocabulary acquisition in young children with Down's syndrome: Speech and Sign. Abstract presented at 9th Worls Congress International Association for the Scientific Study of mental Deficiency, Queensland, Australia. Miolo,G., Sedey A., Murray-Branch, Miller,J. (1992).From babbling to speech: Continuity or discontinuity in children with Down's syndrome. Paper presented at the 9th World Congress of the International Association for the Scientific
Study of Mental Deficiency. Queensland, Australia August, 1992.

Peskett,R. \& Wootton,A.J. (1985) Turn-taking and overlap in the speech of young Down's syndrome children. Journal of Mental Deficiency Research 29 263-273.

Piccirilli,M., D'Alessandro,P., Mazzi,P., Seiarma,T. \& Testa,A.(1991) Cerebral organisation for language in Down's syndrome patients. Corfex (1991) 27,41-47.

Rondal,J. (1988) Down's syndrome In Bishop,D. \& Mogford,K. (Eds) Language Development in Exceptional Circumstances

Sacks,O. (1988) Seeing Voices, Picador.

Vygotsky,L.(1986) Thought and Language (new ed.) Harvard University Press.

\section{New publication \\ April 1993}

\section{The development of language and reading skills in children with Down's syndrome \\ 2nd edition}

\section{Sue Buckley and Gillian Bird with Pat LePrevost and Gilly Williams}

This is a practical guide for parents and practitioners, written by an experienced team of psychologists and speech therapists.

Topics covered in this completely revised edition include:

How do children learn to talk?

What sort of language skills do children with Down's syndrome usually acquire?

What particular difficulties delay the language development of children with Down's syndrome?

Encouraging early language skills

Using signing to develop language and speech

Teaching reading to teach language

Games and activities to encourage language development

While the focus of the book is on how to help children develop effective communication skills, the advice is based on the latest research which is summarised in readable style. The book includes a comprehensive list of research references as an appendix.

Available shortly from the Sarah Duffen Centre, price $£ 6.00+£ 1.00$ postage and packing.

The videotape which accompanies the first edition of the book is still available, price $£ 15.00+£ 1.00$ postage and packing.

Forthcoming:

Two new videotapes

will be available shortly on

Language Development and Developing Literacy 